\title{
Erratum to: The prevalence, temporal and spatial trends in bulk tank equivalent milk fat depression in Irish milk recorded herds
}

Catherine I. Carty ${ }^{1}$, Alan G. Fahey ${ }^{2 *}$, Morgan R. Sheehy ${ }^{3}$, Steve Taylor ${ }^{3}$, Ian J. Lean ${ }^{4}$, Conor G. McAloon ${ }^{1}$, Luke $\mathrm{O}^{\prime}$ Grady $^{1}$ and Finbar J. Mulligan ${ }^{1}$

\section{Erratum}

Following the publication of this article [1], it was brought to our attention that the PDF version of the article unfortunately contained the following error:

Figure 6 had accidentally been replaced with Figure 5, which incorrectly appeared duplicated in the PDF.

The correct Figure 6 is presented below and has been updated in the PDF version of the original article.

\footnotetext{
Author details

${ }^{1}$ School of Veterinary Medicine, University College Dublin, Dublin, Ireland. ${ }^{2}$ School of Agricultural Food Science and Nutrition, University College Dublin, Dublin, Ireland. ${ }^{3}$ Devenish Nutrition, Lagan House, 19 Clarendon Road, Belfast, Northern Ireland. ${ }^{4}$ Scibus Consultancy, 2 Broughton Street, Camden, NSW, Australia.
}

Received: 5 June 2017 Accepted: 5 June 2017

Published online: 13 June 2017

\section{Reference}

1. Carty Cl, et al. The prevalence, temporal and spatial trends in bulk tank equivalent milk fat depression in lrish milk recorded herds. Ir Vet J. 2017;70: 14. doi:10.1186/s13620-017-0092-y.

\footnotetext{
*Correspondence: alan.fahey@ucd.ie

${ }^{2}$ School of Agricultural Food Science and Nutrition, University College Dublin, Dublin, Ireland
} 


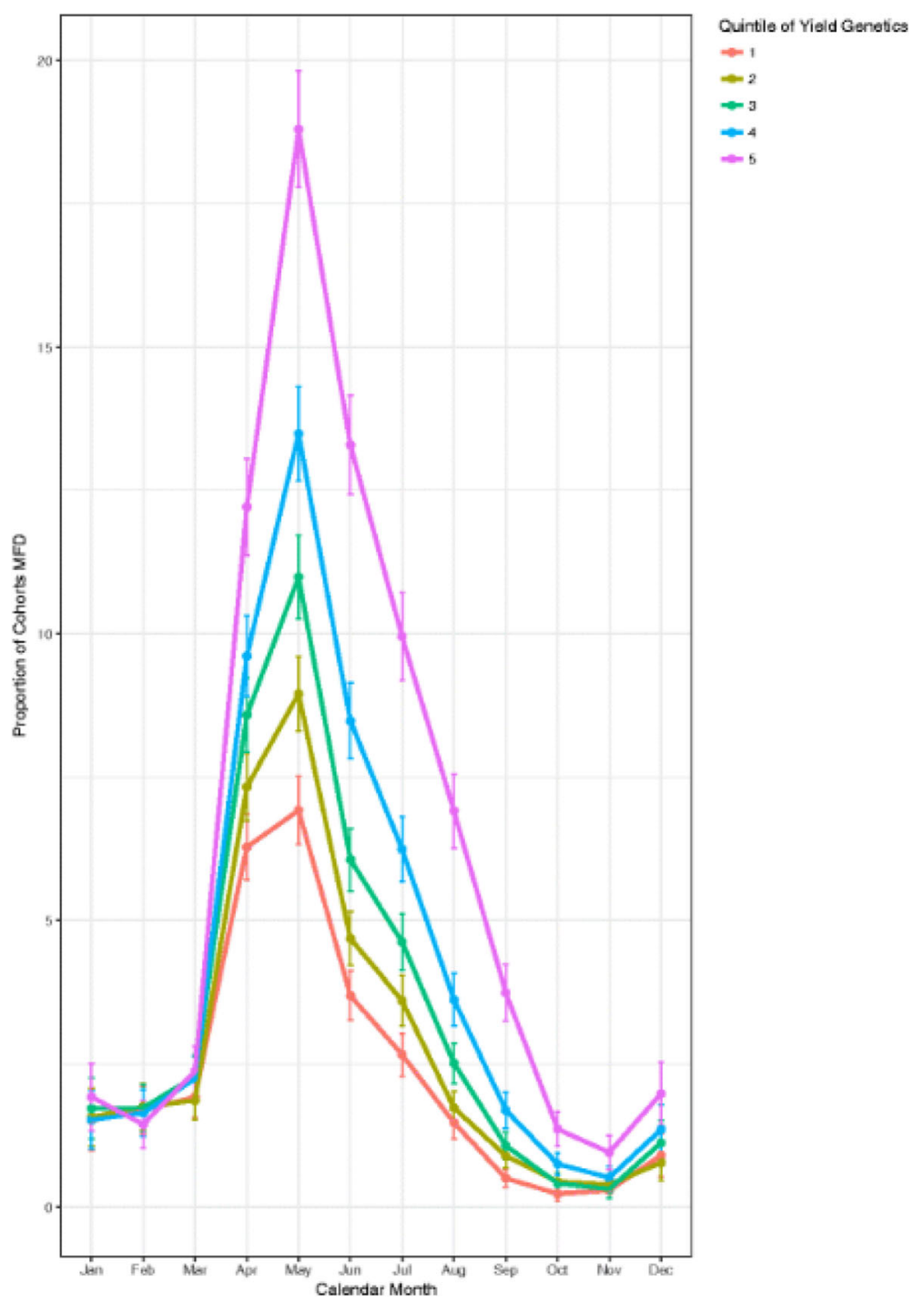

Fig. 6 Monthly prevalence of MFD across within-herd cohorts of cows grouped by Quintile of predicted transmitting ability for milk kilograms with error bars showing 95\% confidence intervals 